Article

\title{
Determinants of Innovation Ecosystem in Underdeveloped Areas-Take Nanning High-Tech Zone in Western China as an Example
}

\author{
Xiaojing Huang ${ }^{1,2,3,4}$, Lei Ma ${ }^{4,5, *}$, Rao Li ${ }^{6}$ and Zheng Liu $4,7, *$ \\ 1 School of Intellectual Property, Nanjing University of Science and Technology, Nanjing 210094, China; \\ huangxiaojing@njust.edu.cn \\ 2 China-ASEAN Institute of Innovation Governance and Intellectual Property, Guangxi University of Finance \\ and Economics, Nanning 530003, China \\ 3 School of Economics and Management, Hechi University, No.42 Longjiang Road, Hechi 546300, China \\ 4 Centre for Innovation and Development, Nanjing University of Science and Technology, \\ Nanjing 210094, China \\ 5 School of Public Affairs, Nanjing University of Science and Technology, Nanjing 210094, China \\ 6 School of Business, Macau University of Science and Technology, Macau 999078, China; \\ 1809853xbb30003@student.must.edu.mo \\ 7 Cardiff School of Management, Cardiff Metropolitan University, Cardiff CF5 2YB, UK \\ * Correspondence: maryma2009@njust.edu.cn (L.M.); Zliu@cardiffmet.ac.uk (Z.L.)
}

Received: 30 August 2020; Accepted: 4 November 2020; Published: 6 November 2020

\begin{abstract}
High-tech zones are an important platform for local governments in China to carry out regional collaborative innovation and an important carrier for the construction of a regional innovation ecosystem. The evolution path of innovation ecosystem in a high-tech zone is divided into three stages: enterprise collection, industrial cluster, and system integration. The innovation subjects form a complex network system that transcends the physical boundary. This paper studies the relationship between innovation input, innovation output, and innovation environment from the perspective of cluster innovation ecosystem structure. Using data mining technology, this paper establishes an index variable system of the innovation ecosystem in a high-tech zone, which includes innovation input, innovation output, and innovation environment. Based on the data of the Nanning National High-tech Zone in China, empirical tests were carried out, using factor analysis and regression analysis to analyze the quantitative relationship between the input, output, and innovation environment of the Nanning High-tech Zone's innovation ecosystem, and to explain the relationship between each other and the overall innovation of the high-tech zone. This research has certain practical significance for enriching and perfecting the theory of industrial clusters and studying the evolution of the innovation ecosystem of high-tech zones from a micro level. It has important, enlightening significance as a reference for the construction of innovative high-tech zones and the enhancement of high-tech zones' independent innovation capabilities.
\end{abstract}

Keywords: innovation ecosystem; collaborative innovation; high-tech zone

\section{The Introduction}

High-tech industrial development zones (hereinafter referred to as "high-tech zones") are special areas that rely on policies and environmental advantages to aggregate innovative resources to promote the development of high-tech industries. From a global perspective, the high-tech zone has become the preferred development mode for various countries and regions to create innovation highlands, 
cultivate innovative enterprises, build innovation ecology, improve innovation performance, and lead economic innovation driven development [1,2].

A number of world-class innovation clusters and benchmarking areas represented by the Silicon Valley and the North Carolina Triangle of the United States, Tsukuba in Japan, Cambridge Science Park in the United Kingdom, Baden Wurtenberg in Germany, Stockholm in Sweden, and Bangalore Software Park in India continue to emerge as an important carrier for building a regional innovation ecosystem. In China, high-tech zones, represented by science and technology parks, high-tech industrial parks, and development zones, are an important platform for local governments to carry out regional collaborative innovation, an important carrier for building regional innovation ecosystems, and an important block for promoting high-quality economic development. The practice of China's reform and opening-up policy for more than 40 years has proven the importance of high-tech zones to China's economic development and their role in gathering, radiating, and incubating innovation has been generally recognized, and has become a leading force in China's construction of an innovative country, exploring the path of independent innovation and promoting innovation driven development [3].

In 2020, the COVID-19 epidemic has had a huge impact on the global economy. The fragility and instability of the existing global industrial chain and supply chain are particularly prominent because of its long and thin structure. In order to prevent the risk of industrial chain rupture, countries are paying more attention to the security of domestic supply chains, and the momentum of anti-globalization and de-globalization is getting stronger. At the same time, the complex changes in the external environment such as the escalation of China-US economic and trade frictions have also brought great uncertainty to China's economic development, and the discussion on the "decoupling" between the two countries has become a hot topic in the academic circles. In this context, it is the focus of discussion by scholars from various countries to improve the global industrial chain and supply chain's anti-risk ability by achieving both a globalized level of labor division and a vertically integrated production relationship in a certain area. As the cluster area of China's science and technology enterprises and the most economically dynamic region, the high-tech zone is undoubtedly the best "test field" in China. Through the reconstruction of the regional innovation chain, the restructuring of the industrial chain, and the reorganization of the supply chain, a regional industrial chain cluster with vitality and international competitiveness will be created, which will contribute wisdom and practical experience to reconstruct global value chain and restore world economic order. However, the lack of innovation ability is the biggest bottleneck for the innovation and development of China's High-tech zones. A series of problems, such as the unreasonable allocation of innovation resources, imperfect innovation network, and lack of innovation environment mechanisms, seriously restrict the improvement of China's high-tech zones' innovation ability [2].

How to build a good innovation ecosystem around the improvement of innovation chain is an important way to improve the innovation ability of high-tech zone. Therefore, studying the internal development law of the innovation ecosystem of high-tech zones and exploring the endogenous mechanism of the generation of the innovation chain of industrial clusters has important practical significance and value for scientifically formulating feasible high-tech zone innovation development policies and promoting the construction of innovative parks. At the same time, it has a certain practical significance to enrich and improve the theory of industrial cluster and study the evolution of innovation ecosystem of high-tech zone from the micro level, and has an enlightening and significant reference role for the construction of innovative high-tech zones and the promotion of independent innovation ability of high-tech zones.

\section{Main Literature Review}

\subsection{Industrial Clusters and Innovation Networks}

The concept of industrial cluster was proposed by Porter, who believed that the industrial cluster could not only reduce transaction costs and improve efficiency, but also create knowledge, improve 
innovation conditions, and promote the formation of new enterprises, which was the fundamental source of a country's global economic competitiveness [4]. The concept of cluster and the externality of cluster was first proposed by Marshall, who believed that enterprises agglomerated due to externalities such as input-output relationships, shared labor pools, and knowledge spillovers $[5,6]$.

Freeman first proposed the concept of innovation network, believing that innovation network is an innovation process within the system based on institutional arrangements. The main element of network connection is innovation cooperation between enterprises, which is an informal relationship [7].The research on innovation networks was subsequently divided into two levels: regional innovation networks and enterprise innovation networks. Regional innovation network refers to "a relatively stable system formed on the basis of long-term formal or informal cooperation and exchange relations between local actors (enterprises, universities, scientific research institutes, local governments and other organizations and their individuals)" [8], focusing on the study of the relationship between the actors in a specific region. For example, the Innovation Network [9] high-tech zone, in Silicon Valley in the United States and Route 128 [10] are the research perspectives based on the network level. Among them, industrial cluster is a phenomenon of industrial growth in which the same industries are highly concentrated in a specific region [11], which can be regarded as the same industrial network research of regional innovation network. Lazzeretti proposed that innovation is mainly generated and developed by the collaboration of all stakeholders of the triple helix, such as scientific research institutions, enterprise clusters, government, and intermediary institutions, through the dynamic tracking of the high technology applied to cultural goods (HTCG) business innovation network in Tuscany, Italy for 15 years [12]. She also pointed out that the correlation between different scientific fields is very important. Innovation is usually carried out in a specific field first, and then becomes incremental innovation in another field through horizontal innovation [12]. The enterprise innovation network refers to "the overall structure of various formal and informal cooperation relationships formed around the enterprise in the process of technological innovation" [13]. It takes the core enterprise as the research starting point and is based on the enterprise-level research perspective.

Today, knowledge has become a key factor in the competitiveness of countries and regions [2]. The main driving force of regional innovation comes from the regional industry-university-research collaborative innovation knowledge network formed by various heterogeneous knowledge resources such as enterprises, universities, and scientific research institutions [2,8]. The regional industry-University-Research collaborative innovation network is organized by governments, enterprises, universities, scientific research institutions and financial institutions etc. It has the common characteristics of internal cooperation, embeddedness, openness, stability, and dependence on the environment $[1,2,8]$. This regional knowledge network can promote the optimal allocation of various heterogeneous knowledge resources in a specific region and create new knowledge, thus becoming an important factor related to regional economic competitiveness and development potential, and also a key factor forming regional advantages [1].

\subsection{Innovation Environment and Innovation System}

Pavlou et al. thought that the innovation environment refers to the sum of various external factors that affect the innovation subject to carry out innovation in the process of innovation [14]. These factors mainly include policy support, intermediary services, financial support, and insurance services [14]. The innovation environment directly determines the innovation efficiency, has a significant impact on the collaborative degree and collaborative participation degree of industry-university-research innovation strategy [15], and is also related to the construction of the innovation system and innovation platform of high-tech zones. The definition of the connotation of the innovation environment studied by scholars is carried out basically from the regional dimension, which can be divided into two levels. One such level is that the innovation environment is a social relationship or network established by the main actors in a certain region through long-term formal or informal interaction and collective learning. Meanwhile, the second level is that the innovation environment refers to the regional environment 
where the subject is located, including cultural environment, infrastructure, market size, management system, policies and regulations, and other elements. The division of the elements of the innovation environment is basically studied from the perspective of hard and soft conditions, that is, the hard elements are composed of infrastructure level and resource conditions etc., while the soft elements are composed of policies, institutions, regulations, and social and cultural values, etc. [16].

Lundvall put forward the concept of the innovation system in the 1980s and, for the first time, studied innovation organizations from the system perspective [17]. The innovation system is a complex system that contains subsystems such as innovation subject, innovation resources and innovation environment [18]. Under the nonlinear interaction, they can form the overall synergistic effect that cannot be achieved by a single subsystem, and realize the process of resource integration, which determines the success of the innovation system to some extent [19]. Ascani et al. analyzed the data of regional innovation in Italy from 2007 to 2012, and proposed that innovation has boundaries in the region. Regional innovation is an interactive process, and knowledge resources are not only generated within the scope of the local economy, but also combined with external investment [20]. This is in sharp contrast to recent anti-globalization views [20].

\subsection{Innovation Ecosystem}

Moore is the first scholar to define the connotation of the innovation ecosystem, and believes that the interdependence between different subjects in the system reflects the characteristics of ecology. He pointed out that the Group organizational ecology formed by innovative enterprises based on certain rules and orientations is the innovation ecosystem [21]. The proposal of this concept has triggered extensive research by scholars. Most scholars believe that the innovation ecosystem is composed of interconnected and interdependent network participants (core enterprises, customers, suppliers, complementary innovators, and regulatory agencies), and at the same time these participants are absolutely dependent on the system environment [22]. Iansiti and Levin believed that each individual in the innovation ecosystem has its own ecological niche in the system, and the change of the enterprise ecological niche will inevitably lead to the change of the whole system [23]. Adner pointed out that the external innovation environment is very important for the construction of innovation ecosystem, and good external environment endows innovation ecosystem with high reliability [24]. Etzkowitz emphasized that all elements of innovation ecology form an isomorphic system, in which the elements interact and depend on each other, and symbiosis creates new dominant elements [25]. Cappellano studied the role of non-profit organizations in cross-border cooperation in the Cascadia Innovation Corridor on the US-Canada border and San Diego-Tijuana on the US-Mexico border, and proposed a new cross-border regional innovation ecosystem Concept, pointing out that non-profit organizations play a primary role in the cross-border innovation ecosystem [26]. Markkula describes the European Commission's program for research and innovation strategies for smart specialization (RIS3) and shows how the Helsinki Region in Finland is using smart specialization, ecosystem orchestration, and the active role of universities to enhance regional innovation and the "smartness" of the region. And believing that it is the active orchestration of the regional ecosystem around concepts such as knowledge co-creation and exploitation, opportunity exploration, and capacity building. It is believed that the active coordination of regional ecosystems around concepts such as knowledge co-creation and development, opportunity exploration, and capacity building makes intelligent regions become more intelligent [27].

The proposal of the innovation ecosystem originated from the deepening of the understanding of the innovation system and the continuous deepening of innovation practice. Innovation ecosystem theory is a theoretical system that absorbs the main viewpoints of ecological theory and evolutionary economics theory, and is the latest achievement of the deepening development of innovation system theory. It highlights the dynamic growth characteristics of innovation system and emphasizes the self-organization nature of innovation system [28]. Innovation ecosystems, like biological systems, have evolved from the random selection of elements into a structured community [29], which is still 
an innovation system in essence. Feng et al. believed that the innovation ecosystem is structurally composed of innovation ecological communities, and the innovation ecological communities are composed of populations with different innovation resources. Innovation ecosystem is characterized by nestedness, multilayer, and multiplicity, etc., and is a typical complex network system that transcends physical boundaries [30]. The innovation ecosystem is an open and complex adaptive system with dynamic evolution. It simulates the economic dynamics of complex relationship, which is represented by the interaction between different innovation subjects, which makes technological development and innovation possible [31]. Open innovation can offset the profit loss caused by risk aversion by sharing profits in the supply chain [32]. Hang proposed that new technologies represented by the Internet of Things, artificial intelligence, and augmented reality will create a Blue Ocean that combines mobility, reduction, growth, and innovation, and further promotes open and integrated innovation initiatives to open up new ecosystem [33]. Du fully proposed an innovation ecosystem that integrates government production, education, and research, emphasizing that the innovation system, network, and environment together constitute an innovation ecosystem. In addition, some scholars have clearly pointed out that the innovation ecosystem is composed of government, researchers, intermediary organizations, enterprises and industrial incubators and other main elements [34].

\subsection{Evaluation System of Innovative Ecosystem in High-Tech Zone}

Foreign scholars have studied the evaluation system of innovation ecosystem in high-tech zones from multiple perspectives. Jarunee studied the Silicon Valley innovation system from the perspective of collaborative innovation, and pointed out that the effective combination of production, education and research is the key to its strong innovation ability [35]; Ricardo et al. believed that the development of high-tech zones has evolved into a multiple interactive development model with innovation and research and development (R\&D) as the basic elements [36]. Wahyuni et al. compared the high-tech zones in Indonesia, Malaysia, and China from the perspective of innovation factors, and concluded that intellectual capital, the degree of support for related industries, and the attitude of the government are the key factors driving the development of high-tech zones [37]; Ben et al. conducted an empirical study on innovation input and innovation output efficiency from the perspective of input and output, and confirmed that insufficient input and excessive input will lead to low efficiency of innovation output, and policy makers should carry out macro-control according to different situations [38].

Chinese scholars have also conducted research from different perspectives. For example, Liu et al. proposed to establish an evaluation system composed of five indicators: knowledge creation ability, knowledge flow ability, enterprise innovation ability, innovation environment and innovation performance [39]. Fan constructed an evaluation system of technological innovation capability of high-tech zones with 16 indicators, and made a comprehensive evaluation of 52 high-tech zones in China by using the method of principal component analysis [40]. Fang believes that the evaluation of innovation ability in high-tech zones is mostly considered from the perspective of "input-output", and the internal mechanism is not clear enough, so she established the evolution model of innovation ability in high-tech zones [41]. Xiao et al. established an evaluation system including three first-class indicators of innovation input, innovation output and incubation capacity and 13 secondary indicators based on the analytic hierarchy process to evaluate the innovation ability of high-tech zones [39].

In fact, among the existing research results on the evaluation of innovation ecosystem in high-tech zones, there are more researches on the overall evaluation from the macro system level, and few from the perspective of industrial cluster structure to analyze the internal mechanism of the formation of innovation ability by combining the measurement of innovation ability and innovation output from the perspective of industrial cluster structure. In this paper, data mining technology is used to explore the internal mechanism of platform innovation ecosystem evolution from the perspective of high-tech zone innovation ecosystem construction, which has important enlightening significance and reference for improving innovation ability, improving innovation performance, and realizing high-quality development of the high-tech zone. 


\section{Research Design}

\subsection{Study the Design of Variables}

This research regards the high-tech zone as an innovation platform, and believes that the evolution of its innovation ecosystem depends on the functional connection formed by division of labor and cooperation between platform participants. This functional connection is mainly based on two related relationships. One is based on the vertical correlation between innovation subjects in the industrial chain. The other is based on the horizontal association between the manufacturers of similar products. On this innovation platform, innovation subjects such as universities, scientific research institutions and enterprises undertake the tasks of scientific and technological innovation, product research and development, and product mass production, which constitute the innovation chain. The related production enterprises undertake the task from productization to scale, and the industrial chain is composed of enterprise clusters around a certain industry. It is precisely because of the division and cooperation of different subjects in the industrial chain and innovation chain that the whole process of products from "scientific and technological research and development-achievement transformation-production and sales-user experience-upgrading iteration" forms an organic system in the form of a virtuous cycle, i.e., an innovation ecosystem. Only if the structure of this system is reasonable, can the evolution and development of high-tech industrial clusters be realized. The connotation of the evolution process of this system is the expansion of levels, that is, the inclusive relationship between hierarchy and its interaction. Based on the above analysis, we define the innovation ecosystem of high-tech zone into four levels, namely, innovation species (enterprise), innovation population (enterprise collection), innovation community (industrial cluster), and innovation environment (ecosystem). The evolution path of the innovation ecosystem in the high-tech zone is divided into three stages: the formation of populations, i.e., the aggregation of enterprises, the formation of communities, i.e., industrial clusters, and the formation of environments, i.e., the innovation ecosystem. Each stage is an in-depth development on the basis of the previous stage, and the system formation stage is the process of establishing interactions between innovative ecological communities and realizing value co-creation, as shown in Figure 1.

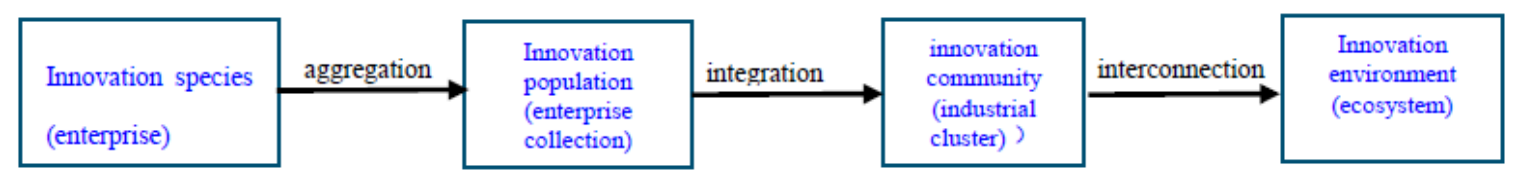

Figure 1. The evolution path of the innovation ecosystem in the high-tech zone.

The enterprise is one of the basic components of the innovation ecosystem and the most important subject for continuous innovation of the system. The value creation ability of innovation ecosystem depends on the integration degree of innovation ability of participating enterprises, and its quality determines system innovation ability. The innovation population is the collection of different enterprises in the same industry. Whether the ecological chain of an industry is complete, whether the various links are matched, and whether the allocation of "quality" and "quantity" of enterprises in each link is reasonable all have a significant impact on the innovation ecosystem. The innovation community includes not only the industrial community composed of related industries, but also the knowledge subject community based on knowledge innovation, such as universities and scientific research institutions, as well as the community of intermediary institutions that provide services and support for innovation. These communities form an organic unity through complex relationships, and their reasonable structure plays a key role in whether the cluster innovation ecological chain (network) of a high-tech zone can play a role. The innovation environment is the external condition on which the cluster lives. The cluster is communicating with the external environment all the time.

In conclusion, the innovation ecosystem of high-tech zone is an organic whole of the interaction and influence between innovation communities and innovation environment within the region as 
well as within the innovation communities. The creation of a good innovation environment through government investment in high-tech zones will promote the development of innovation capabilities of high-tech zone clusters. On the contrary, the independent management and development of the innovation subject in the cluster will further create a good innovation environment, thus forming a good innovation ecosystem. To be specific, various innovation organizations in the region are closely linked and interact with each other and their related environments. Through capital exchange, knowledge transfer and talent flow, they become a dynamically balanced whole with a specific space, stable structure, and innovation functions. The innovation ecosystem of high-tech zone is a kind of cooperation mode of innovation, value-added and diversity, which can increase the competitiveness and development speed of the innovation community participating in the innovation ecosystem, and obtain more opportunities and unparalleled profits in the industry. It advocates open innovation with the core of "cooperation and win-win" and truly realizes the win-win mechanism of all parties. Only by optimizing the industrial chain and creating an innovation ecosystem in accordance with the requirements of improving the innovation chain can it form an effective driving force to support sustainable innovation.

\subsection{Design of the Measurement Index System}

Ou et al. took 56 national high-tech zones in China as the empirical research objects, and established the evaluation index system of endogenous function and explicit ability of cluster innovation system of high-tech zones [42]. According to the selected 13 indicators for evaluating the endogenous function of the collaborative innovation of high-tech zone clusters and 10 indicators for evaluating the explicit ability of the high-tech zone, a comprehensive evaluation study of the national high-tech zones in China has been carried out [42]. This set of evaluation index system mainly conducts horizontal comparative research on high-tech zones. Since the longitudinal evolution research of innovation ecosystem in high-tech zones is rarely involved in the academic circle, it is necessary to discuss from the perspective of the evolution of innovation ecosystem in a single high-tech zone.

Based on the understanding of the innovation ecosystem of high-tech zones and the availability and scientificity of data, this paper draws on the evaluation variable index system of cluster innovation ecosystem of high-tech zone proposed by Ou et al. [43], and optimizes and establishes a set of innovation ecosystem evaluation index system for High-tech Zone individuals. Starting from the composition of innovative ecosystem, the index system includes three dimensions: innovation input, innovation output and innovation environment. The index system of innovation input is constructed from three aspects: innovation resource input (enterprise collection), innovation population structure input (industrial cluster), and innovation species relationship input (innovation network). The innovation output indicator system is constructed from two aspects: economic efficiency and sustainable development. The innovation environment indicator system is constructed from three aspects: policy and financial environment, knowledge environment, and intermediary service environment. In order to reveal the quantitative relationship between input, output, and the innovation environment of the innovation ecosystem in high-tech zones as comprehensively and systematically as possible, based on domestic and international literature, this paper combines the concept of innovation ecosystem, and designs a preliminary index system which includes 20 indexes of innovation input, 12 indicators of innovation output and 16 indexes of innovation environment. Using factor analysis and multiple linear regression analysis, this paper attempts to find the quantitative relationship between the input, output, and innovation environment of the innovation ecosystem. Specific evaluation indicators are shown in Table 1. 
Table 1. Evaluation Index System of Platform Innovation Ecosystem in High-tech Zone.

\begin{tabular}{|c|c|c|}
\hline \multirow{4}{*}{ Innovation Input } & Innovative Species Input & Number of enterprises in the district (V1) \\
\hline & & $\begin{array}{l}\text { Number of enterprises with R\&D centers (V2) } \\
\text { Number of research institutes in the district (V3) }\end{array}$ \\
\hline & & $\begin{array}{l}\text { R\&D expenditure in the district (V4) } \\
\text { R\&D input intensity (V5) } \\
\text { Number of R\&D staff in the district (V6) } \\
\text { The proportion of senior technical personnel (V7) }\end{array}$ \\
\hline & $\begin{array}{l}\text { Input of Innovative Population Structure } \\
\text { Innovative Population Relations Input }\end{array}$ & $\begin{array}{l}\text { Number of leading industries (V8) } \\
\text { Enterprise density within the industry (V9) } \\
\text { Industrial relevancy degree (V10) } \\
\text { Intensity of Industry-University-Research (V11) } \\
\text { Linkage Degree of intra-industry cooperation (V12) }\end{array}$ \\
\hline \multirow[t]{2}{*}{ I } & Economic benefits & $\begin{array}{l}\text { Total industrial production in the region (W1) } \\
\text { Annual net profit in the region (W2) } \\
\text { New product sales revenue (W3) } \\
\text { Export volume (W4) } \\
\text { Annual tax payable (W5) } \\
\text { technical income (W6) }\end{array}$ \\
\hline & & $\begin{array}{l}\text { Number of Patent Authorizations in the Area (W7) } \\
\text { Net profit growth rate (W8) } \\
\text { Return on assets (W9) }\end{array}$ \\
\hline \multirow{9}{*}{ Innovation environment } & Policy and financial environment & Government investment in R\&D (E1) \\
\hline & & Intensity of government R\&D investment (E2) \\
\hline & & The proportion of loans from financial institutions in R\&D funds (E3) \\
\hline & & Amount of foreign direct investment (E4) \\
\hline & knowledge environment & Full time equivalent of scientific and technological personnel (E5) \\
\hline & & Number of patent applications for scientific and technical personnel (E6) \\
\hline & & Number of core journal papers published by scientific and technical personnel (E7) \\
\hline & Intermediary Service Environment & Number of national incubators (E8) \\
\hline & & Number of National Productivity Promotion Centers (E9) \\
\hline
\end{tabular}

\section{Empirical Analysis}

\subsection{Nanning National High Tech Zone—A Short Specificity of the Research Area}

In 1992, Nanning High-tech Zone was approved as a national high-tech zone in China. In the past 20 years, relying on 35 colleges and universities, 17 scientific research institutions above the provincial level, and more than 120,000 scientific and technological talents and researchers, Nanning University District has built a multi-level innovation platform composed of Industrial Technology Research Institute, industrial innovation technology alliance, innovation incubator (accelerator) and technology innovation platform. The park has initially formed four industrial clusters in the field of intelligent manufacturing, new generation information technology, life and health, and science and technology services. The park has promoted a large number of enterprises to participate in the construction of the "Belt and Road" to achieve rapid development, provide important support for the innovative development of Nanning and even Guangxi, and become a powerful engine for Guangxi's economic development. By 2017, there are more than 6000 enterprises settled in Nanning High-Tech Zone, with a GDP of more than 100 billion yuan, ranking 37th among China's 147 national high-tech zones, No.4 among 19 national high-tech zones in Western China, No.18 in China's sustainable development capacity, and No.36 in knowledge creation and technological innovation capacity, which has been upgraded for five consecutive years. The practice of Nanning High-tech Zone in constructing regional innovation ecosystem not only provides experience for the underdeveloped areas in western China to catch up with and develop, but also enriched and developed the theoretical system of regional collaborative innovation development of underdeveloped countries or regions.

\subsection{Data Acquisition and Standardization}

Considering that China's National high-tech zone has entered the stage of all-round innovation and development since 2012, in order to further reveal the evolution trend of innovation ecosystem in national high-tech Zone in time and space, this study selected Nanning, Guangxi as the empirical 
research object. According to the designed index system, the original data were collated and collected by combining the 2013-2017 Statistical Yearbook of China High-tech Zone, China Torch Statistical Yearbook, China Science and Technology Statistical Yearbook, China Regional Competitiveness Report, and other published materials to obtain relevant original data. In order to eliminate the analysis errors caused by different dimensions, this study adopts the common statistical standardization method to dimensionless the original data.

\subsection{Data Analysis}

\subsubsection{Factor Analysis}

In this study, 12 variables affecting innovation input, 9 variables of innovation output and 9 variables of innovation environment are selected as original variables, and R-type factor analysis is carried out on related variables. This paper attempts to explain the complex relationship among 30 obvious variables or observable variables by using three common factors, namely, innovation input comprehensive factor, innovation output comprehensive factor and innovation environment comprehensive factor.Spss19.0 software was used for statistical analysis. The number of factors was selected as " 3 ", and the extraction method was "maximum likelihood method". Under the rotation type, the "factor variance maximum method" was selected.

Firstly, the fitness test of factor analysis was carried out. Bartlett test of sphericity and Kaiser Meyer Olkin measure of sampling adequacy were used. Calculating the correlation matrix between the variables, the KOM values of the three are $0.847,0.813$, and 0.806 , which are all greater than 0.6 , indicating that the internal reliability of the sample index system is relatively good, and it is more suitable for factor analysis. The $\mathrm{P}$ values of Bartlett's sphericity test are all 0 , and it can be considered that there is a significant correlation between the variables. According to Bartlett's sphericity test and $\mathrm{KOM}$ test, both are suitable for factor analysis. According to the standardized correlation coefficient matrix, the factor characteristic root and variance contribution rate of innovation input, output and innovation environment in the high-tech zone are obtained, as shown in Table 2.

Then the factor load of each variable is calculated and analyzed. The main factor is subjected to the factor rotation of the load matrix by using the Varimax orthogonal rotation method to obtain the rotated load matrix, as shown in Table 3.

The load represents the degree to which the factor explains each variable. The larger load (positive or negative) indicates that the factor has a strong influence on the variate, while the smaller load (positive or negative) indicates that the factor has a weak influence on the variate. The rotated load matrix shows the structural relationship between innovation input, innovation output, and indicators in the innovation environment. For the comprehensive factor of innovation investment, the number of enterprises in the park V1, the number of enterprises with R\&D centers V2, the number of universities and scientific research institutions V3, the R\&D expenditure V4, the number of R\&D personnel V5, the number of R\&D personnel in the park (V6), and so on have a large load on the first main factor. These six indicators are all related to the input of innovation elements in the innovation ecosystem of high-tech zone, which can be named as the input factor of innovation elements. The proportion of scientific and technological personnel (V7) and the number of leading industrial clusters (V8) have a large load on the second main factor. These two indicators reflect the situation of industry-university-research collaborative innovation and can be named as the innovation structure input factor. The density of enterprises in the industrial cluster (V9), the degree of enterprise relevance in the industrial cluster (V10), the strength of industry-university research cooperation (V11), and the degree of cooperation among enterprises in the industrial cluster (V12) have a relatively large load on the third main factor. The four indicators reflect the internal and external structure of the industry and the proportion of resource allocation in the innovation ecosystem, and can be named as innovation relationship input factors. 
Table 2. Factor characteristic root and cumulative variance contribution rate $\%$.

\begin{tabular}{|c|c|c|c|c|c|c|c|}
\hline \multirow{2}{*}{ Comprehensive Factors } & \multirow{2}{*}{ Factors } & \multicolumn{3}{|c|}{ Unrotated Initial Factor } & \multicolumn{3}{|c|}{ Main Factor Extracted after Rotation } \\
\hline & & Characteristic Root & Contribution Rate & Cumulative Contribution Rate & Characteristic Root & Contribution Rate & Cumulative Contribution Rate \\
\hline \multirow{3}{*}{ Innovation input } & $1(\mathrm{~F} 1)$ & 5.253 & 51.422 & 51.422 & 4.285 & 40.102 & 40.102 \\
\hline & 2(F2) & 1.467 & 14.181 & 65.603 & 1.623 & 18.634 & 58.736 \\
\hline & $3(\mathrm{~F} 3)$ & 1.165 & 9.925 & 75.528 & 1.495 & 16.562 & 75.298 \\
\hline \multirow{2}{*}{ Innovation output } & 1(F1) & 5.056 & 61.892 & 61.892 & 5.023 & 60.158 & 60.158 \\
\hline & 2(F2) & 1.038 & 15.012 & 76.904 & 1.153 & 15.136 & 75.294 \\
\hline \multirow{2}{*}{ Innovation environment } & 1(F1) & 3.825 & 47.629 & 47.629 & 3.512 & 43.911 & 43.911 \\
\hline & 2(F2) & 2.193 & 26.472 & 74.101 & 2.356 & 30.045 & 73.956 \\
\hline
\end{tabular}

Table 3. Factor load matrix after rotation.

\begin{tabular}{|c|c|c|c|c|c|c|c|c|c|}
\hline \multirow[b]{2}{*}{ Variate } & \multicolumn{3}{|c|}{ Main Factor Load Matrix of Innovation Input } & \multicolumn{3}{|c|}{ Load Matrix of Main Factor of Innovation Output } & \multicolumn{3}{|c|}{ Main Factor Load Matrix of Innovation Environment } \\
\hline & 1 & 2 & 3 & Variate & 1 & 2 & Variate & 1 & 2 \\
\hline V1 & 0.932 & 0.214 & 0.091 & W1 & 0.980 & 0.145 & E1 & 0.925 & -0.112 \\
\hline $\mathrm{V} 2$ & 0.942 & 0.249 & 0.156 & W2 & 0.945 & 0.062 & E2 & 0.895 & 0.328 \\
\hline V3 & 0.926 & 0.201 & 0.102 & W3 & 0.923 & 0.016 & E3 & 0.881 & 0.061 \\
\hline V4 & 0.832 & 0.302 & 0.332 & W4 & 0.903 & 0.301 & E4 & 0.806 & -0.023 \\
\hline V5 & 0.756 & 0.241 & 0.072 & W5 & 0.945 & -0.112 & E5 & 0.757 & 0.240 \\
\hline V6 & 0.735 & 0.235 & 0.119 & W6 & 0.854 & 0.015 & E6 & 0.132 & 0.919 \\
\hline V7 & 0.396 & 0.788 & 0.088 & W7 & 0.332 & 0.903 & E7 & 0.109 & 0.911 \\
\hline V8 & 0.411 & 0.765 & -0.165 & W8 & 0.275 & 0.882 & E8 & 0.455 & 0.613 \\
\hline V9 & 0.285 & 0.348 & 0.741 & W9 & 0.167 & 0.771 & E9 & 0.296 & 0.515 \\
\hline V10 & 0.226 & 0.122 & 0.703 & & & & & & \\
\hline V11 & 0.154 & -0.305 & 0.698 & & & & & & \\
\hline V12 & 0.248 & -0.018 & 0.575 & & & & & & \\
\hline
\end{tabular}


In terms of the comprehensive factors of innovation output the industrial production value in the park (W1), corporate net profit (W2), new product sales revenue (W3), park exports (W4), annual corporate income tax (W5), technology and transfer income (W6) etc. have a larger load on the first main factor. These six indicators all reflect the economic benefits of the high-tech zone, so they can be named as output benefit factors. The number of patents granted (W7), net profit growth rate (W8) and profit margin of enterprise assets (w9) have a great load on the second main factor. These three indicators reflect the potential of sustainable development of the high-tech zone, which can be named a growth potential factor.

On the comprehensive factor of innovation environment, government R\&D investment amount (E1), government R\&D investment intensity (E2), proportion of R\&D funds from financial institutions (E3), foreign direct investment (E4), full-time equivalent of scientific and technological personnel (E5) have a large load on the first main factor, which reflects the policy and financial support of High-tech Zone, which can be named policy and financial environment Environmental factor. The number of patent applications (E6), the number of high-level papers published by scientific and technological personnel (E7), the number of national innovation incubators (E8), and the number of national innovation and entrepreneurship centers (E9) in the region have a large load on the second main factor, which reflects the knowledge environment of the region where the high-tech zone is located, which can be named as the knowledge environment factor.

\subsubsection{Regression Analysis}

In order to explore the quantitative relationship between the input and output of the innovation ecosystem and the innovation environment, using the score data of the principal factors, a multiple linear regression method was used to perform regression analysis on the three variables of innovation input, innovation output, and innovation environment. This article uses the following two models to test the causal relationship between the variate:

Model 1: Innovation Output = a1 Innovation Input + b1 Innovative environment $+\mathrm{C} 1$

Model 2: Innovation Input $=$ a2 Innovative environment $+\mathrm{C} 2$

Among them, a1, B1, and A2 represent the coefficients in the regression equation respectively, $\mathrm{C} 1$ and C2 represent the intercepts in the regression equation respectively. In this paper, SPSS19.0 is used for regression analysis. The results of operation are shown in Tables 2 and 3, respectively.

It can be seen from Table 4 that the adjusted R2 of model 1 and model 2 are 0.756 and 0.653 respectively, which means that the independent variable can explain $75.6 \%$ and $65.3 \%$ of the variance of the criterion variable respectively. At the same time, the F value of the two models reached a significant level, indicating that the interpretation of the model is good.

Table 4. Model Summary.

\begin{tabular}{ccccccccc}
\hline & R & R2 & Adjusted R2 & Standard Error of Estimation & R2 Change Quantity & F Change & Significant & DW Test \\
\hline Model 1 & 0.872 & 0.784 & 0.756 & 0.334 & 0.784 & 77.623 & 0.000 & 1.993 \\
\hline Model 2 & 0.803 & 0.715 & 0.653 & 0.206 & 0.715 & 90.155 & 0.000 & 1.281 \\
\hline
\end{tabular}

In the coefficient table of model 1 (see Table 5), it can be seen that the standardized coefficient of innovation input variable is 0.705 , and the $\mathrm{T}$ value test reaches a significant level, indicating that innovation input has a great impact on innovation output, and there is a positive correlation between them. The standardization coefficient of innovation environment is 0.203 , and the $t$-value test does not reach the significant level, but it does not necessarily mean that there is no relationship between innovation environment variables and innovation output variables. In fact, in the analysis, the product difference correlation coefficient between innovation environment variables and innovation output variables is $0.751(p=0.000)$ and reaches a significant level, while the coefficient in the regression model does not reach the significant level, which indicates that there may be some relationship 
between innovation environment variables and innovation input variables, which is verified in model 2. In model 2, the standardization coefficient of innovation environment as an independent variable to the standard variable of innovation input is 0.735 , and the standard error is only 0.082 . The $T$ value test passes the significant level, which shows that the innovation environment has a strong positive effect on innovation input. In summary, the relationship between the three can be expressed by two equations:

Innovation output $=0.705$ innovation input +0.203 innovation environment

Innovation input $=0.798$ innovation environment

Table 5. Model coefficients.

\begin{tabular}{|c|c|c|c|c|c|c|c|}
\hline \multirow{2}{*}{$\begin{array}{c}\text { The Name of the Variables } \\
\text { Innovation Input } \\
\text { (Model 1) }\end{array}$} & \multicolumn{2}{|c|}{$\begin{array}{l}\text { Unstandardized Coefficients } \\
b \text { Value Standard Error }\end{array}$} & \multirow{2}{*}{$\begin{array}{c}\begin{array}{c}\text { Standard Coefficient } \\
\text { Beta Distribution }\end{array} \\
0.705\end{array}$} & \multirow{2}{*}{$\begin{array}{c}\text { t Value } \\
6.442\end{array}$} & \multirow{2}{*}{$\begin{array}{c}\text { Important Degree } \\
0.000\end{array}$} & \multicolumn{2}{|c|}{$\begin{array}{l}\text { Collinear Statistics } \\
\text { Tolerance VIF }\end{array}$} \\
\hline & 0.954 & 0.176 & & & & 0.374 & 2.683 \\
\hline $\begin{array}{l}\text { Innovation Output } \\
\text { (Model 1) }\end{array}$ & 0.239 & 0.142 & 0.203 & 1.755 & 0.087 & 0.374 & 2.683 \\
\hline $\begin{array}{l}\text { Innovative environment } \\
\text { (Model 2) }\end{array}$ & 0.735 & 0.082 & 0.798 & 9.566 & 0.000 & 1.000 & 1.000 \\
\hline
\end{tabular}

\section{Conclusions, Enlightenment and Deficiency}

This paper has established the index variable system of the innovation ecosystem of high-tech zones, which includes innovation input, innovation output, and innovation environment. It has used factor analysis and regression analysis to analyze the quantitative relationship between the input and output of the innovation ecosystem and the innovation environment. Through the factor analysis and regression analysis of the data of Nanning High-Tech Zone, we can draw the following conclusions:

(1) From the perspective of innovation input and innovation output, the correlation between innovation output and innovation input is higher than that with innovation environment. It can be seen from Equation (1) that innovation input largely determines the quantity and quality of innovation output of high-tech zone. Innovation output mainly depends on the good performance of input factors of innovation elements. This is mainly because the input factors of innovation factors indicate the scale and quality of the main elements invested in the innovation ecosystem. It shows that the quality of innovation investment in Nanning High-Tech Zone is constantly improving, but there is not much investment in innovation structure input factor and innovation relationship input factor. It shows that in the past, Nanning High-Tech Zone only focused on attracting innovative subjects to gather in the region through a large number of preferential policies, forming a superficial "cluster". It has not paid enough attention to the establishment of a reasonable industrial ecological structure and production-university-research platform, and it has not built an innovation network through the innovation chain and the industrial chain among the innovation subjects. This will not be conducive to the improvement of the innovation chain and industrial chain, as well as the coordination between innovation chain and industrial chain, which will hinder its sustainable development in the future.

(2) From the perspective of innovation ecological environment, the direct influence of the innovation environment of Nanning High-tech Zone on innovation output is relatively small. However, it can be seen from Equation (2) that the innovation environment has a great influence on the innovation input. The good performance of policy and financial environment factors promotes the innovation subject's input in innovation elements, and promotes innovation output by promoting innovation input. However, on the other hand, it is weak in terms of the knowledge environment factor and intermediary service environment factor, which indicates that it ignores the construction of "soft environment", such as knowledge environment and cultural environment, which will bring hidden trouble to the improvement of innovation environment in the future, which is not conducive to the sustainability of innovation ability. 
(3) Under the background of high-quality development, in order to realize the transformation and upgrading of industrial structure and cultivate the new driving force of economic growth, the Nanning High-Tech Zone needs to adapt to the new characteristics of the new round of industrial revolution, such as the change of innovation technology path and competition pattern, the increase of environmental uncertainty, and the substantial increase of information scale and exchange speed. First of all, the way of simply expanding the scale of investment must be changed. There is a need to lay down the pace, adjust the structure, build the network, pay attention to the construction of reasonable enterprise community gradient and complementary industrial system in the ecosystem of the high tech zone, so as to find the best proportion of resource allocation. Secondly, attention should be paid to the establishment of industry-university-research platforms, and establish a research platform shared by schools (scientific research institutions) through policies to stimulate and support cooperation and innovation among different organizations. The park should improve the construction of science and technology service intermediary, build a bridge of industry university research information exchange, promote the development of regional technology market, and form a virtuous circle of knowledge creation, knowledge capitalization, industrialization, and value co creation.

(4) In the development of the innovation ecosystem of a high-tech zone, attention should be paid to the construction of various intermediary service organizations (such as venture capital institutions and innovation and entrepreneurship service institutions), build a bridge between enterprises, knowledge, and funds, and form a good policy and financial environment. In addition, there should be long-term effort to promote the construction of "soft environment" such as knowledge environment and cultural environment for the innovation development of high-tech zones. A group should be formed with knowledge creation as the goal in the region where the high-tech zone is located. They form formal and informal network relationship and perfect knowledge chain system based on mutual knowledge demand. A social environment should be created to attract talents and promote the generation of new ideas, new knowledge, and new technologies. Guided by the market, a four-helix innovation structure of "university (scientific research institute)-enterprise-government-intermediary service agency" is formed, which promotes the process from knowledge generation to value realization, thereby promoting the improvement of the innovation output capacity of the high-tech zone ecosystem.

(5) From the evaluation of the innovation ecosystem of Nanning High-Tech Zone, it can be seen that systematic engineering should be adopted for each main factor that affects the innovation ecosystem of the high-tech zone. Attention should be paid to the coordinated development of the three main factors under the innovation input, form a reasonable industrial structure, and build an open and organically connected innovation network beyond the physical boundaries. At the same time, it is necessary to attach great importance to the construction of an institutional environment, a cultural environment, and an innovation environment, and to improve the quality and quantity of inputs to the ecosystem of high-tech zones. This not only has reference value for the sustainable development of high-tech zones in underdeveloped provinces in western China, which is similar to Nanning High-Tech Zone, but also has reference value for the development of high-tech zones in underdeveloped countries and regions.

It is true that there are still some shortcomings in this study, such as the limitation of data availability and the insufficient representation of the research samples in China's high-tech zones, which makes it difficult to completely objectively reflect the overall situation of China's high-tech zones. In the following research, we will continue to make up for the deficiencies, explore other factors and their mechanism of regional collaborative innovation, and accelerate the rational application and effective implementation of China's high-tech zones in the process of building innovation ecosystem.

Author Contributions: Conceptualization, L.M. and X.H.; methodology, L.M. and X.H.; formal analysis, L.M., Z.L. and R.L.; investigation, X.H.; resources, X.H.; data curation, X.H.; writing-original draft preparation, X.H.; writing-review and editing, L.M. and X.H.; visualization, X.H.; supervision, L.M. and Z.L.; project administration, L.M.; funding acquisition, L.M. All authors have read and agreed to the published version of the manuscript. 
Funding: This research was funded by Major Project of National Social Science Foundation of China (NSSF), Project Name "Research on the Mechanism and Path about Technological Standard and Intellectual Property Synergistically Promoting Digital Industry Innovation", grant number 19ZDA078.

Acknowledgments: Special thanks to SOItmc2020 conference and Lei Ma and Zheng Liu who held Special Session 6 that provided an opportunity for academic exchanges. Thanks for the funding from Project "Research on the Mechanism and Path about Technological Standard and Intellectual Property Synergistically Promoting Digital Industry Innovation", grant number 19ZDA078.

Conflicts of Interest: The funders had no role in the design of the study; in the collection, analyses, or interpretation of data; in the writing of the manuscript, or in the decision to publish the results.

\section{References}

1. McPhillips, M. Trouble in Paradise? Barriers to Open Innovation in Regional Clusters in the Era of the 4th Industrial Revolution. J. Open Innov. Technol. Mark. Complex. 2020, 6, 84. [CrossRef]

2. Ma, L.; Liu, Z.; Huang, X.; Li, T. The Impact of Local Government Policy on Innovation Ecosystem in Knowledge Resource Scarce Region: Case Study of Changzhou, China. Sci. Technol. Soc. 2019, 24, 1-24. [CrossRef]

3. Liu, Z.; Chen, X. Research on the Relationship between innovation Ecosystem and Innovation Efficiency in Science and Technology Parks. Sci. Res. Manag. 2015, 36, 26-31.

4. Porter, M.E. Competitive Advantage of Nations, 10th ed.; Free Press: New York, NY, USA, 1990.

5. Marshall, A. Principles of Economics, 5th ed.; MacMillan: London, UK, 1920.

6. Potter, A.; Watts, H.D. Revisiting Marshall's Agglomeration Economies: Technological Relatedness and the Evolution of the Sheffield Metals Cluster. Reg. Stud. 2012, 48, 603-623. [CrossRef]

7. Freeman, C. Networks of innovators: A synthesis of research issues. Res. Policy 1991, 20, 499-514. [CrossRef]

8. Gai, W.; Wang, J. Discuss the role of regional innovation networks in the development of high-tech SMEs in China. China Soft Sci. 1999, 9, 102-106.

9. Sun, S. Research on the Operation Mechanism of the Innovation Network in High-tech Zones. Policy Res. Explor. 2003, 1, 22-23.

10. Li, X. High-tech Innovation Network: Comparison of US Silicon Valley and Route 128. Open Times 2000, 4, 23-28.

11. $\mathrm{Xu}, \mathrm{K}$. Industrial clusters and competitiveness in an open economy. China Ind. Econ. 2001, 11, $22-27$.

12. Lazzeretti, L.; Capone, F. R\&D networks in High Technology applied to Cultural Goods in Tuscany. A Social Network Analysis. Ital. J. Manag. 2016, 34, 75-99.

13. Wang, D. The evolution and governance of enterprise innovation networks: A literature review. Sci. Res. Manag. 2001, 5, 96-103.

14. Pavlou, P.A.; Elsawy, O.A. Understanding the elusive black box of dynamic capabilities. Decis. Sci. 2011, 42, 39-273. [CrossRef]

15. Xiong, X.; Li, D. Innovation environment, collaborative innovation mechanism and collaborative innovation behavior of Seed Enterprises: An Empirical Study Based on Factor Flow Perspective and structural equation model. Sci. Technol. Manag. Res. 2016, 36, 158-165.

16. Zhao, Y.; Chen, K.; Li, Y. Review of innovation environment assessment: Concept, index and method. Sci. Sci. Manag. Sci. Technol. 2019, 40, 89-99.

17. Lundvall, B.K. Product innovation and user-producer interaction. Ind. Dev. Res. Ser. 1985, 31, 3-38.

18. Samara, E.; Georgiadis, P.K.; Bakouros, I. The Impact of Innovation Policies on the Performance of National Innovation Systems: A System Dynamics Analysis. Technovation 2012, 32, 624-638. [CrossRef]

19. Sepulveda, F.; Gabrielsson, M. Network Development and Firm Growth: A Resource-based Study of B2B Born Globals. Ind. Mark. Manag. 2013, 42, 792-804. [CrossRef]

20. Ascani, A.; Bettarelli, L.; Resmini, L.; Balland, P.A. Global Networks, Local Specialisation and Regional Patterns of Innovation. Res. Policy 2020, 49, 31-54. [CrossRef]

21. Moore, J.F. Predators and prey: A new ecology of competition. Harv. Bus. Rev. 1993, 71, 75-86. [PubMed]

22. De Vasconcelos Gomes, L.A.; Facin, A.L.F.; Salerno, M.S.; Ikenami, R.K. Unpacking the Innovation Ecosystem Construct: Evolution, Gaps and Trends. Technol. Forecast. Soc. Chang. 2018, 136, 30-48. [CrossRef]

23. Iansiti, M.; Levien, R. Strategy as Ecology. Harv. Bus. Rev. 2004, 82, 68-81.

24. Ander, R. Match your Innovation Strategy to your Innovation Ecosystem. Harv. Bus. Rev. 2006, 84, 83-98. 
25. Etzkowitz, H. Silicon Valley at risk? Sustainability of a Global Innovation Icon: An Introduction to the Special Issue. Soc. Sci. Inf. 2013, 52, 515-538. [CrossRef]

26. Cappellano, F.; Makkonen, T. Cross-border regional innovation ecosystems: The role of non-profit organizations in cross-border cooperation at the US-Mexico border. GeoJournal 2020, 85, 1515-1528. [CrossRef]

27. Markkula, M.; Kune, H. Making Smart Regions Smarter: Smart Specialization and the Role of Universities in Regional Innovation Ecosystems. Technol. Innov. Manag. Rev. 2015, 10, 7-15. [CrossRef]

28. Zeng, G.; Ge, Y.; Liu, L. From “innovation system" to “innovation ecosystem”. Sci. Res. 2013, 1, 4-11.

29. Mei, L.; Chen, J.; Liu, Y. Innovation ecosystem: Origins, Knowledge evolution, and Theoretical framework. Sci. Res. 2014, 12, 1771-1779.

30. Feng, W.; Yang, S. High-tech industry agglomeration measurement and comparative research: An empirical analysis based on China's 2007-2017 data. J. Ind. Technol. Econ. 2020, 6, 154-160.

31. Chen, X.; Liu, Z. Observation on the development of Science and Technology Parks in China based on the viewpoint of innovation ecosystem. China Soft Sci. 2014, 11, 123-136.

32. Yoon, S.; Jeong, S. Effects to implement the open-innovation coordinative strategies between manufacturer and retailer in reverse supply chain. J. Open Innov. Technol. Mark. Complex. 2017, 3. [CrossRef]

33. Hang, S.P. Technology convergence, open innovation, and dynamic economy. J. Open Innov. Technol. Mark. Complex. 2017, 3, 2-12.

34. Du, D. Cracking the Password of Innovation. Wen Hui Bao 2012, 11, 21.

35. Jarunee, W. Commercialization Strategies of Technology: Lessons from Silicon Valley. J. Technol. Transf. 2010, 2, 225-236.

36. Ricardo, M.C.; Pablo, R.P. Twenty-five years of Science Parks in Spain toward a New Model of Development. J. Rev. Bus. Inf. Syst. 2011, 15, 17-24.

37. Wahyuni, S.; Astuti, E.S. Critical Outlook at Special Economic Zone in Asia: A Comparison between Indonesia, Malaysia, Thailand and China. J. Indones. Econ. Bus. 2013, 28, 395-397.

38. Ben, T.M.; Wang, K.F. Interaction Analysis among Industrial Parks, Innovation Input and Urban Production Efficiency. Asian Soc. Sci. 2011, 5, 56-71. [CrossRef]

39. Liu, X.; Zhang, X.; Wang, Q. Research on the Evaluation of Innovation Ability in China's High-tech Zones based on analytic Hierarchy Process. Econ. Issues 2012, 1, 31-34.

40. Fan., B. Research on the Evaluation of Technological Innovation Ability of National High-tech Zone. Stud. Sci. Sci. 2003, 21, 667-671.

41. Fang, Y. Research on the Formation Mechanism of Innovation Ability in high-tech Zones. Sci. Technol. Manag. Res. 2010, 12, 2-3.

42. Ou, G.; Lin, L.L.; Ren, F.; Wang, L. Research on the correlation evaluation between endogenous function and explicit capability of cluster collaborative innovation system in high tech Zone. Sci. Technol. Prog. Policy 2014, 19, 620-628.

43. Ou, G.; Lin, L.L.; Ren, F.; Wang, L. Research on the Quantitative Relationship between the Input, Output and Innovation Environment of the Cluster Innovation Ecosystem in High-tech Zone. Sci. Technol. Manag. Res. 2016, 7, 172-177.

Publisher's Note: MDPI stays neutral with regard to jurisdictional claims in published maps and institutional affiliations.

(C) 2020 by the authors. Licensee MDPI, Basel, Switzerland. This article is an open access article distributed under the terms and conditions of the Creative Commons Attribution (CC BY) license (http://creativecommons.org/licenses/by/4.0/). 